\title{
Dieter Sicker, Klaus-Peter Zeller, Hans-Ullrich Siehl, Stefan Berger: Natural Products. Isolation, Structure, Elucidation, History
}

\author{
Edward R. Adlard ${ }^{1}$
}

๑) Springer-Verlag GmbH Germany, part of Springer Nature 2019

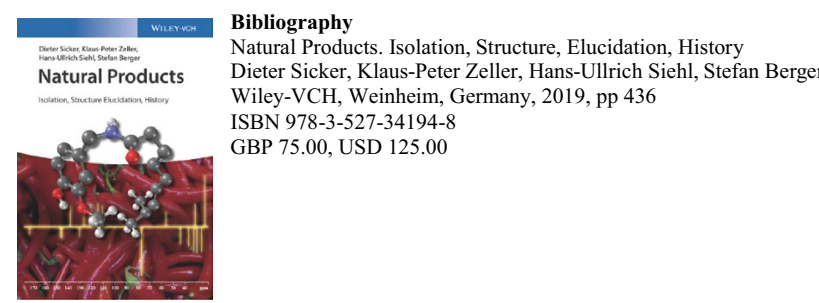

This book is a collection of 20 essays first published in German journals. Three of the four authors are associated with the University of Tübingen and until I received this book I only knew it as the university at which the late Ernst Bayer was a professor. Bayer was the first person in Germany to carry out analysis by gas-liquid chromatography. However, thanks to Wikipedia I now know that Tübingen is an ancient university town somewhat akin to Oxford and Cambridge and like them has a large student population.

The book is divided into six sections of different lengths. Section 1 "Alkaloids", Section 2 "Coloured Compounds", Section 3 "Carbohydrates and Glycosides", Section 4 "Terpenoids" and Section 5 "Aromatic Compounds". These are arbitrary divisions since there is obviously overlap between them and here "aromatic" means compounds with an aroma, not necessarily with a benzene ring. Section 6 on "Quantum Chemical Calculations" is only six pages long and, as the name suggests, it is different from all the preceding chapters.
The first five chapters follow along similar lines with many colour illustrations and potted biographies of well-known scientists such as Willstätter and less well-known ones such as Pelletier. (I should point out here that there are no less than three excellent indexes at the end of the book one of which gives a list of these names). I have not counted the number of colour plates but there must be at least a hundred and those such as a pomegranate tree (Page 9, Figure 1.1-2) and an orange tree (Page 375, Figure 5.1-2) make it a most artistic and attractive volume. These latter plates would not be out of place in a book on botany. There are also scores of diagrams of chemical structures. In addition to all this, there is a considerable amount of information about the analysis of many compounds by chromatography, mass spectrometry and NMR and also on pharmacognosy (see Chapter 4.4 on artemisinin).

This is an outstanding book that should be on the shelves of all chemists. I can best summarise it by reproducing part of Wiley's description on the rear cover "Educating and entertaining this full-colour textbook turns the learning process into a real pleasure, not only for students in natural products chemistry but also experienced professionals".

One can only hope that the four polymath authors will write another 20 articles and publish them in due course.

Publisher's Note Springer Nature remains neutral with regard to jurisdictional claims in published maps and institutional affiliations.
Edward R. Adlard

e.adlard77@btinternet.com

1 Burton, UK 